\title{
OS IMPACTOS DA INTRODUÇÃO DA MOEDA METÁLICA NO MÉXICO COLONIAL*
}

\author{
Leila Maria Franca \\ Doutoranda em Arqueologia no Museu de Arqueologia e Etnologia da USP
}

\begin{abstract}
Resumo
O presente artigo analisa aspectos da introdução da moeda metálica no México Central, com base em documentação do século XVI. Partindo do estudo da Noção de Valor, que contempla a questão do valor atribuído aos objetos monetários pré-hispânicos, enfoca justamente, a relação conflitante entre duas noções de valor opostas: a indígena e a mercantilista européia, e o que dela resulta na construção de um novo sistema de valores no contexto colonial.
\end{abstract}

\section{Abstract}

This article proposes a new insight over ther metal coin introduction process in Central Mexico, in accordance to the XVI century documents. Starting from the Notion of Value analysis, it deals with the value of the prehispanic monetary objetcs and the relation between two contradictory notions of value - indigenous and european - providing elements to understand the construction of a new value system in colonial period.

\section{Pallavras-Chave}

México - Objetos Monetários - Conquista Espanhola - Moeda - Mercado

\section{Keywords}

Mexico - Monetary Objects - Spanish Conquest - Metal Coin - Market

\footnotetext{
*Artigo baseado em estudo mais amplo: Transformações da Noção de Valor na Mesoamérica: os 'Objetos Preciosos' como Intermediários nas Trocas Indígenas e o seu Encontro com a Moeda Metálica. São Paulo, FFLCH/USP, 1999 (Dissertação de Mestrado).
} 
'Nadie en jadel Nadie en oro se convertirá: en la tierra quedará guardado. Todos nos iremos/ allá, de igual modo. Nadie quedará, Conjuntamente habrá que perecer/ nosostros iremos así a su casa.' Nezahualcóyotl, Senhor de Texcoco

D um modo geral, poder-se-ia afirmar que, com a Conquista Espanhola da América - mais especificamente, do México - ocorre um processo gradativo de substituição monetária através da introdução da moeda metálica, a qual, aos poucos, vai substituindo os objetos monetários tradicionais; processo esse, que, aliado a outros fatores da conquista, irá desencadear mudanças dramáticas na concepção de vida e de valores indígenas. Embora tal afirmação seja correta, ocorre, no entanto, que a questão comporta nuances difíceis de se imaginar, sem o adequado manejo das fontes. Na verdade, esse é um processo extremamente complexo que envolve inúmeros problemas, os quais encontram-se estreitamente relacionados ao quadro geral de transformações decorrentes do encontro cultural.

O processo de substituição monetária foi, sem dúvida muito mais complexo do que supõe a bibliografia corrente, em função de uma série de fatores como a eficiência e conveniência do dinheiro pré-hispânico, a escassez de metal precioso enviado na quase totalidade para a metrópole, a necessidade de se criar e regulamentar uma moeda oficial - o que envolve a atuação de uma estrutura política centralizada - e a falta de consenso da população indígena em torno do valor do novo dinheiro.

$\mathrm{Na}$ verdade, a substituição monetária não é um processo unilateral e rigidamente dirigido e mais ainda, por uma moeda específica, e sim um fenômeno que comporta influências recíprocas, circunstâncias imprevistas e recursos monetários diversos, dentro da lógica informal da realidade colonial. Por outro lado, já os primeiros contatos entre europeus e americanos - antes mesmo da introdução da moeda-constituíram um vetor de reorientação cultural e valorativa ao imprimir a lógica européia e condicionar as práticas indígenas. Tal fenômeno, como se sabe, provocou um desencadeamento de transformações irreversíveis, das quais a noção de valor é apenas um aspecto. 
As transformações do valor podem, portanto, ser apreendidas por meio do fator monetário, mas muito além disso, pela própria noção de valor que comporta aspectos não materiais, vinculados ao mundo material e ao conjunto de relações que ele intermedia.

Este artigo constitui uma apreciação daquilo que as fontes disponíveis nos permitem detectar acerca da introdução do metal - e da problemática que lhe concerne - e do encontro de duas noções opostas de valor, no México Central, mais especificamente, a Cultura Mexica, mais conhecida como Asteca. Veremos como a introdução da noção de valor econômico ao mesmo tempo em que se vincula à moeda metálica, antecede sua presença material e lhe prepara, por assim dizer, o terreno. Quanto às inúmeras implicações culturais e sociais decorrentes desse processo, que se desdobrariam ad infinitum, poderá o leitor apreender nas linhas e entrelinhas da análise do valor.

\section{Os Objetos Monetários no México Pré-hispânico.}

Como sabemos, o comércio entre os antigos mexicanos era uma atividade bastante desenvolvida. Ao lado do tributo, era responsável pelo abastecimento do império de gêneros de subsistência e prestígio ${ }^{1}$. Subdividia-se em basicamente três tipos: comércio de longa-distância, no qual se destacavam os artigos de luxo; o mercado (tianguiz) onde se vendiam desde gêneros alimentícios até escravos e jóias; e a troca cerimonial responsável pela circulação de objetos preciosos (Gernet 1948; Mauss 1971) os entre elementos da elite. Tal importância pode, ainda, ser reforçada pelo fato de estarem essas atividades diretamente relacionadas à expansão imperial: a uma camada de comerciantes profissionais - os pochteca, responsáveis pelo comércio de longa-distância - era confiada a tarefa de um comércio oficial, além de funções militares como espiões em terras distantes - o que, sem dúvida, apesar de

\footnotetext{
${ }^{1}$ Por Império entende-se a área de domínio da Tríplice aliança formada por Tenochtitlán, Tezcoco e Tlacopan. Apesar de constituir o termo objeto de discussão, nós o empregamos no sentido "um estado que abarca grande território e incorpora... sociedades antes autônomas e culturalmente heterogêneas, uma das quais domina sobre as outras"(Conrad e Demarest 1990:18).
} 
sua condição comum (não nobre), lhes conferia uma posição de destaque na organização social mexica.

Numa sociedade com tal desenvolvimento comercial - e mais que isso, na qual o comércio constituía, inclusive, um dos aspectos-chave da organização imperial (Berdan 1975) - o instrumento monetário, desempenhava um papel fundamental na intermediação dessas relações as quais, na verdade, extrapolavam a simples noção de aquisição de bens para a sobrevivência, por duas razões básicas. A primeira delas refere-se ao fato de que dentro da organização da sociedade asteca como as demais sociedades arcaicas que se caracterizam, em termos gerais, pela presença do Estado e de uma sociedade estratificada (Polanyi 1968; Dalton 1967), as trocas envolvem muito mais do que a mera satisfação das necessidades e estão de algum modo vinculadas a outras esferas da vida ou diluídas nas relações sociais (Mauss 1971; Polanyi 1968). Mesmo diante da presença de um mercado desenvolvido, as sociedades arcaicas caracterizavam-se, ainda, pela retenção de práticas culturais e organização social tradicionais (Dalton 1967: 266).

Uma segunda razão é que, a própria noção de valor incorporada por esses objetos - objetos preciosos - têm sua origem vinculada ao uso cerimonial, religioso, político (Einzig 1966; Pryor 1977; Quiggin 1949; França 1999) razão, inclusive de sua eleição como instrumento monetário.

Assim, diversos objetos - perecíveis e não perecíveis - faziam a intermediação dessas relações dentro dos limites do Império e a documentação relativa ao México Central, de um modo geral, menciona os seguintes: mantas (um tipo específico, denominado quachtli), plumas preciosas, cacau, contas de jade e outras pedras verdes (chalchihuitl), machados de cobre (hachitas), guizos metálicos, e ouro sob diversas formas, especialmente em discos, um adorno para lábios em forma de águia e em pó, que atuavam nos vários níveis de troca, de forma muito particular. Igualmente aos objetos monetários de diversas culturas, esses itens preenchiam funções específicas para cada tipo de transação. Eram dinheiros para fins especiais que, no México, revezavam-se basicamente entre as esferas da subsistência e de prestígio, uma vez que as fontes parecem indicar que o comércio de longa-distância prescindia do uso monetário (Chapman 1976). 
A semente de cacau destacava-se no âmbito do mercado e constituía a moeda típica das transações do dia-a-dia. Existe apenas uma menção em Sahágun, sobre a troca cerimonial de cacau em grão, (1975: IX, VI, 7) e duas relativas à espátula de mexer cacau, (IX, IV, 9; IX, VI, 7), mesmo assim em um contexto específico de festa dos mercadores - o que é elucidativo quanto à sua vinculação às atividades mercantis. Ainda dentro dessa esfera operava o ouro em pó e - embora não exclusivamente - as mantas, já que essas circulavam sistematicamente em contextos cerimoniais. $\mathrm{O}$ ouro em pó parece ter sido um artigo de troca tipicamente de mercado, provavelmente na qualidade de matériaprima para posterior utilização não-monetária (França 1999).

Uma outra esfera - de caráter cerimonial e essencialmente vinculada à noção de prestígio - refere-se a um comércio nobre, em que o objeto é apenas o intermediário material de uma circulação mais abrangente, de significados múltiplos, relacionados ao universo religioso, mítico, social e político. Da mesma forma em que as trocas de subsistência mantém o equilíbrio entre produção, o papel desta última é promover o equilíbrio social, ordenando o universo através de trocas simbólicas (Mauss 1971). Dentro dela estão presentes os contextos, de dom e pagamento de resgate, multas, sangue, nupcial, entre outros (França 1999).

As plumas, por exemplo, parecem ter constituído, mais que todos os demais objetos, uma moeda escolhida para pagamentos - especialmente as plumas de quetzal - tendo em vista a sua importância na ornamentação da elite guerreira.

O chalchihuitl (contas de jade e demais pedras verdes) ao que tudo indica, pertenceria a uma circulação nobre, aparecendo freqüentemente em contextos e trocas cerimoniais, embora pudesse figurar como mercadoria no tianguiz. De qualquer maneira, de acordo com algumas fontes (Sahagún e Torquemada), seu uso era proibido para as camadas não privilegiadas - o que leva a crer que sua aquisição deveria sofrer algum tipo de regulamentação por meio de regras suntuárias.

Os objetos de ouro (com exceção do ouro em pó e em barra) e, possivelmente, o guizo, - embora os dados não o demonstrem diretamente - pela sua condição de ornamento, inscrevem-se nessa categoria. 
A manta, por sua vez, teria desempenhado um papel intermediário. Era o único objeto que transitava nas duas esferas de circulação, seja no mercado, ou na circulação nobre, por uma razão muito específica: se por um lado, constituía objeto de culto, de dom, de pagamento, impregnado de simbolismo, por outro (provavelmente devido à sua grande importância nesses contextos) constituía o padrão de valor entre os mexicanos - fato comprovado pela sua presença prioritária nos registros de tributos relativos a todas as localidades, como o ítem básico e obrigatório, que encabeça as listas, muito provavelmente devido ao papel do algodão como símbolo de riqueza. Essa função lhe garantia um acesso privilegiado à esfera do mercado.

Por último, restam-nos algumas considerações sobre o ouro. Não obstante valioso no México Antigo bem como em toda a Mesoamérica, não era de forma alguma o símbolo de riqueza por excelência (França 1999). Ao seu lado havia um série de outros objetos que expressavam as idéias de riqueza, nobreza, status, tanto quanto ou mais que o ouro, como é o caso do jade e das plumas. Além disso, apesar de valioso para os antigos mexicanos, o ouro jamais representou o papel de equivalente universal - fenômeno, aliás, desconhecido aqui, uma vez que seu contexto de circulação, na América, estaria longe do sistema mercantil de uma sociedade capitalista, em que as razões de mercado predominam e dirigem as relações sociais. Embora a economia indígena movimentasse um grande volume de comércio, é provável que apenas uma parte muito pequena, se fazia por intermédio do ouro. Diferentemente do que ocorria na Europa moderna - onde o ouro desempenhou um papel muito específico num contexto de acumulação primitiva - para a sociedade indígena, esse seria apenas mais um dos materiais empregados como meio de troca. Aqui, seu valor era de um tipo muito particular, vinculado aos contextos mágico-míticos e de prestígio - dentro de um sistema sócio-econômico no qual os diversos objetos atendem a fins muito específicos.

Percebemos, portanto, que uma característica essencial desses objetos, ou melhor, do chamado dinheiro primitivo é que, ao contrário do dinheiro moderno o equivalente universal de Marx (1980-81) - este possuía esferas de atuação muito específicas, de modo que um objeto, como a semente de cacau, por exemplo, era 
empregado no mercado mas não no comércio nobre. Esse é um detalhe fundamental para a compreensão do Contato visto sob a ótica monetária, uma vez que é justamente nessa diferença básica, entre o objeto monetário (para fins especiais) e a moeda metálica (universal) que repousa a origem da problemática da substituição monetária. O primeiro sustenta a multicentralização das trocas, dito de outro modo, a existência das várias esferas de circulação; o segundo promove a simplificação e a unificação do sistema sob a direção soberana do mercado (Dalton 1967; Bohannan 1976). Aquele possui um valor tradicional fincado no mito, nas práticas religiosas e no prestígio, estando vinculado com precisão, à justeza das relações sociais indígenas. Este último, traz consigo a abstração do valor que é uma mera convenção, e cuja realização última é a submissão das diversas esferas da vida, bem como das relações sociais à lógica mercantil.

Do encontro entre ambos, na América, a sociedade indígena não teve muitas escolhas, mas resistiu vigorosamente, como as fontes do século XVI, vistas sob uma nova ótica, nos permitem observar.

\section{A Moeda Introduzida na América}

O peso ou castelhano - moeda de ouro pesada em 4,60 gramas - constituiu, desde o início, a unidade monetária da América (Farrés 1986: 320).

Mesmo diante da escassez ou inexistência de moeda cunhada, cumpria a função de padrão de valor, razão pela qual, foram as mantas prontamente substituídas nessa função. Para fins de circulação na América, eram fabricados os lingotes que substituíam as moedas cunhadas (Farrés 1983: 324). Uma outra unidade bastante citada nas fontes do século XVI era o tomin, moeda de ouro que valia 1/8 do peso.

Octavio Gil Farrés, fundamentado nas obras de Antonio Herrera (1726-30) e Manuel Orozco y Berra (1980), conta que nos primeiros anos da Colônia, (provavelmente em 1522) Cortez emitiu as primeiras moedas por conta própria, fato que veio a conhecimento público poucos anos depois, por ocasião de um processo movido contra ele em 1526 (Farrés 1986:320). Em 1523, foram enviadas pela Coroa algumas moedas da Espanha; mas a unidade corrente na América continuou sendo 
o lingote de ouro que deveria circular com o selo real, prova de legitimidade com relação ao pagamento do quinto (Farrés 1986:321).

Farrés, comenta o uso dos lingotes de ouro ou tepuzque (ouro misturado com cobre) até o ano de 1536 - ano de criação da Casa da Moeda do México. É muito provável que esta situação tenha perdurado por todo o século XVI.

Com a criação da Casa da Moeda - pelo Vice-Rei Antonio de Mendoza, ex-funcionário da Casa da Moeda de Granada - foram cunhadas as primeiras moedas a partir dos 1000 marcos de prata cedidos pelo Rei. Quanto às moedas de ouro, embora servissem de padrão de valor, sua cunhagem só foi autorizada no ano de 1675.

Mediante tal situação, como, afinal, se comportavam as transações cotidianas em um contexto de substituição monetária?

Dentre a documentação relativa ao século VI, os testamentos são de particular importância, uma vez que, em função de sua própria natureza (de inventariar riquezas) nos permitem vislumbrar o universo monetário do período. Além desses, outros documentos municipais, de transferências territoriais, regulamentação dos mercados. Os documentos aqui analisados - uma amostragem pequena, é verdade, mas que pode nos introduzir na questão - pertencem à coletânea intitulada Beyond the Codices, composta de textos nahuatl traduzidos por A J.Anderson, F. Berdan e J. Lockhart (1976).

O Testamento de don Julián de la Rosa de 1566 - inventaria uma série de objetos que deverão ser vendidos para pagar missas após a sua morte, registrando a seguinte conclusão:

E quando isso tudo tiver sido vendido, tudo a seu preço, quando tiverem tirado disso cinco missas, com o muito dinheiro que sobrar, os padres às vezes se lembrarão daqueles que devem receber caridade. (Anderson, Berdan e Lockhart 1976: 47).

A forma vaga de se referir à riqueza, por meio de termos e expressões como dinheiro e seu preço reflete a indefinição quanto aos valores do período. Na verdade, em comparação com documentos posteriores, observa-se nesse texto, uma ausência completa de referências a unidades monetárias espanholas, indicando ao lado do inventário dos objetos preciosos - uma penetração ainda muito superficial 
do novo dinheiro no universo indígena. Embora a quantia não seja citada, sabemos que os preços dos artigos, com relativa exceção daqueles vendidos no mercado, já se expressavam em pesos e tomins - apesar de não circularem, por essa época, necessariamente em moedas. Por outro lado, é importante lembrar - como veremos adiante em outro documento - que havia uma equivalência básica entre a unidade espanhola e os grãos de cacau. Um pouco adiante, inclusive, o testador refere-se a uma taxa recebida de seus dependentes para quem foram doadas suas terras, e entre os itens recebidos constam 200 grãos de cacau (Anderson, Berdan e Lockhart 1976: 51).

A título de comparação, podemos citar um outro testamento - de Doña Catalina de Sena, de Coyoacán, datado do ano de 1588 , portanto um pouco posterior - que se refere às unidades tomins e pesos, e não cita nenhum dos objetos tradicionais. Apesar de passados vinte anos, deve-se levar em conta as variações locais na intensidade do processo aculturativo.

Os documentos territoriais constituem um outro exemplo dessa indefinição monetária: por um lado, encontramos instrumentos de doações, confirmações de posse, divisões, e por outro, aqueles que se referem à venda expressa em moeda espanhola. Mas não deixa de ser significativo que diversas doações são efetuadas por volta da metade do século XVI, ou seja, no período inicial da colônia: o valor das terras ainda não era necessariamente um valor monetário. Naturalmente, esse fenômeno está ligado, também, à desvalorização das terras provocadas pela baixa populacional, o que nos permite constatar que esse era mais um fator a interferir no processo de assimilação de uma nova concepção de valor.

Se as terras, por essa época, não possuíam um valor econômico, outros artigos já haviam se transformado em mercadoria: em 1575, Juan Alvaro, da região de Coyoacán, doa terras à Igreja, mas avalia sua casa em '140 pesos em dinheiro' e relata compras e vendas em pesos in cash (Anderson, Berdan e Lockhart 1976: 113-115).

Em 1547, o Registro do Conselho de Tlaxcala comunica a decisão do corregedor em exigir a cunhagem de um selo com o símbolo da cidade para selar as correspondências; a multa por atraso na sua confecção deveria ser de "20 pesos em moeda" 
(Anderson, Berdan e Lockhart 1976: 119). Essa especificação, pressupõe, naturalmente, a existências de outras formas de pagamento.

Entre as cartas do século XVI, há uma correspondência - Carta do conselho de Huejotzingo para o Rei, de 1560 - em que a cidade se queixa do excesso de tributação. Faz-se referências a pesos 'em dinheiro' e 'tributo em ouro, sessenta peças' esclarecendo, inclusive, que aquela província não produz ouro, o que torna a situação, para eles, ainda mais complicada (Anderson, Berdan e Lockhart 1976: 185-187).

\section{0 caso específico do Mercado}

Relativamente ao tianguiz (mercado), a Lista de preços do mercado estabelecida pelo juiz de Tlaxcala em 1545 vem lançar luz sobre a política espanhola a respeito dessa importante instituição indígena. Assim como no período pré-hispânico, nos primeiros tempos da colônia, impunha-se a tarefa de regulamentar o tranguiz a fim de se evitar desordens e abusos. Como o mercado mantinha-se praticamente limitado ao uso indígena, a unidade monetária permaneceu sendo o cacau. Nesse documento, todos os preços estão avaliados em e devem ser trocados por cacau, mas isso talvez não impedisse que, na disponibilidade ou por conveniência, tanto o cálculo quanto o pagamento pudessem ser feitos em moeda, já que a equivalência que encabeça a lista dos preços é a seguinte:

'Um tomin vale 200 sementes de cacao cheias, ou 230 sementes de cacau murchas.' (Anderson, Berdan e Lockhart 1976: 211).

Percebe-se um certo isolamento do tranguiz em relação à sociedade colonial em diversos aspectos. Os próprios espanhóis, naturalmente, somente chegavam ali com suas leis, por meio de intérpretes. Por isso a permanência da utilização das unidades indígenas era natural e necessária. Mas quando se tratava de qualquer tipo de contato ou transação com espanhóis, o pagamento deveria ser efetuado em metal. Um exemplo disso é que, enquanto os preços e transações no mercado eram fixados em cacau, no caso de multa por infração, pagava-se em pesos de ouro (Anderson, Berdan e Lockhart 1976: 213). Na verdade, como no caso do Perú, estudado por 
Wachtel (1971), essa era uma das formas de convencer os indígenas a integrar-se ao mundo espanhol: para estar quites com as autoridades espanholas, os indígenas precisavam se dedicar a novas práticas que lhes permitissem obter o metal. Por outro lado a própria equivalência cacau=tomin, já é sintomática da penetração dos valores espanhóis no mercado, e da lenta estratégia de monetização em todas as esferas.

Um outro documento, também relativo a Tlaxcala - Os registros do Conselho Municipal, de 1547 - refere-se à regulamentação do mercado e determinação de mercadorias vendáveis, ou não, naquele local. A respeito da fiscalização da venda de artigos tradicionais por algum mercador de fora, diz a passagem:

E eles ordenaram que qualquer negociante que vier aqui para vender cacau, mantas, saias, blusas, ou outros artigos que trouxer, se algum comerciante daqui comprá-los, deverá comunicar às autoridades; então imediatamente deverá ser anunciado como ele os comprou, e da mesma forma, em troca de que irá vendêlos; e o governador, alcaides, conselheiros e senhores governantes [tlatoque] irão ao corregedor e lhe deixarão [o caso] para que determine ordens que beneficie a cada um. (Anderson, Berdan e Lockhart 1976: 123).

À primeira vista, o texto parece referir-se puramente à necessidade de regulamentar a circulação do cacau, mantas e demais artigos de algodão, que constituíam gêneros importados cuja negociação, anteriormente à conquista, estava nas mãos dos pochteca. Mas, por trás da preocupação em fiscalizar e conter esse tipo de comércio, estaria, certamente, a intenção de controlar a vida monetária da região, devido ao caráter monetário do cacau e das mantas - os dois objetos que mais circulavam no período pré-hispânico, ambos, inclusive, com um emprego extremamente difundido e oficializado no mercado.

De qualquer maneira, essa é uma tarefa na qual os espanhóis não obtiveram sucesso: Paul Einzig comenta o testemunho de um viajante em Oaxaca que, no século XVIII, relatou não somente o uso do cacau como meio de troca, quanto o controle de sua produção com o intuito de manter alto o seu valor (1966). Menciona o autor a existência de testemunhos sobre a continuidade na sua utilização monetária no século XIX (Anderson, Berdan e Lockhart 1976: 175) e quiçá existam comunidades que o utilizem como instrumento de troca, ainda nos dias de hoje. 


\section{A Complexidade da substituição monetária}

Em diversos documentos ainda, vemos expressões como 'pesos em ouro' que atestam a diversidade do meio circulante espanhol, como um agravante ao já complicado quadro de valores, embora aquele possuísse um elemento comum: o metal (ouro, cobre, a mistura dos dois e a prata). Mesmo assim, se somarmos, primeiro, a descaracterização do valor dos objetos indígenas; segundo, a tolerância condicionada pela conveniência; e por último, a diversidade do dinheiro espanhol em função da escassez e de uma política de cunhagem deficitária (Moreno 1978; Farrés 1986) percebemos o quanto essa experiência pode ter sido confusa e incompreensível à população indígena.

Parece claro que a questão da mudança da noção de valor é tanto mais complicada por não se limitar simplesmente à reelaboração por parte da população indígena, mas por envolver também uma relativa variabilidade e instabilidade do padrão espanhol as quais implicam necessariamente a tolerância em relação a certas unidades indígenas.

Parece não haver dúvidas, portanto, de quanto foi problemática a transição de uma economia indígena nos moldes tradicionais à uma economia monetária. Como tratamos do tema específico do dinheiro - que para nós não é apenas um conceito objetivo ou um meio de troca de bens, mas um fenômeno sociológico e até mesmo psicológico, já que pressupõe a crença em um valor que é, na verdade, uma convenção - defendemos que o processo de substituição das unidades indígenas pela moeda foi extremamente complexo, envolvendo muitos outros aspectos sociais, constituindo, portanto, uma via a mais para a compreensão do encontro cultural. Pensamos que as afirmações que comumente se fazem, de que a moeda foi adotada com extrema facilidade, feitas por historiadores a posteriori (Gibson 1991; Rojas 1987), são declarações fáceis, práticas e utilitárias, que passam por alto fenômenos e processos da mudança cultural que merecem uma análise mais profunda.

\section{Trocas e transformações da noção de valor: o relato do Conquistador e as primeiras 'fraturas' na noção de valor tradicional}

Muito antes, porém, das primeiras tentativas de se introduzir o metal como dinheiro universal (seja em forma de moeda ou de lingotes), a noção de valor européia era já 
incutida na população indígena, através das experiências da Conquista. Desde os primeiros contatos, indígenas e espanhóis se envolveram em um diálogo extremamente elucidativo quanto às primeiras mudanças na noção de valor: a troca de presentes.

Nesses primeiros encontros, portanto, delineava-se, já, uma transformação na valorização e utilização dos objetos de troca tradicionais. Pode-se observar, a partir da análise dos contextos de troca, que tipo de distorção ocorria em relação a cada objeto, ou seja, a manipulação de cada um deles, segundo as conveniências do contato.

É impressionante como um simples primeiro contato entre duas culturas vem inevitavelmente acompanhado de inúmeras distorções, próprias da tentativa de compreender (e abordar) o outro, principalmente se levarmos em conta que, como bem observa Todorov, existe aí um encadeamento terrivel, onde compreender leva a tomar, e tomar a destruir.... (1988:123). O fato é que essas distorções que acompanham mesmo as primeiras abordagens, desencadeiam uma série de outras que levarão, nesse caso, à descaracterização das trocas e, aos poucos, da própria forma de conceber o dinheiro e o valor. Em termos de troca, essas primeiras distorções intromissões no sistema indígena - poderiam ser melhor formuladas através de pelo menos seis questões que consideramos fundamentais na análise da mudança do valor:

1) para quem os indígenas passam a abrir mão de seus objetos preciosos? 2) em troca de quê? 3) e por quê? E no sentido inverso: 4) a quem - socialmente falando - os espanhóis transferem esses bens? 5) em troca de quê? 6) e por quê?

Parece repousar aí o caos valorativo que se instalou nas primeiras décadas da colônia - o que naturalmente, tem explicações na fusão das duas formas diferentes de conceber valor.

É possível perceber que o uso tradicional dos objetos por parte dos indígenas continuou de certa forma em vigor, mas o fato, por exemplo, de passar-se a presentear o estrangeiro ou dele receber presentes constitui por si só uma grande descaracterização, que implicará inevitavelmente em outras. O texto de Bernal Diaz del Castillo oferece inúmeros exemplos disso. Resta esclarecer o fato de que dentre os objetos 
ou materiais com funções monetárias, somente as mantas, as plumas, o chalchihuitl e o ouro são mencionados pelo cronista.

As mantas aparecem com bastante freqüência neste documento. É notável aqui, frente aos demais documentos, a ausência quase absoluta de intercâmbio comercial envolvendo mantas; estas são mencionadas, quase sempre, como artigo de presente. Embora saibamos que as mantas constituíam um artigo especialmente cotado para a troca de presentes entre os antigos mexicanos, essa discrepância deve-se, provavelmente à intervenção espanhola. Se durante o primeiro século de colonização as unidades indígenas representavam um instrumento conveniente para a estabilidade da economia colonial (Gibson 1991) durante a Conquista - não esqueçamos - essas eram as moedas correntes dentro de uma região na qual espanhóis tinham que obter a sua sobrevivência. Além disso, esses objetos constituíam também importantes instrumentos de negociação entre os dois lados. Cortez, prontamente percebeu que necessitava armazenar objetos valiosos para presentear segundo o costume nativo e ser bem sucedido em suas estratégias de conquista.

Assim, encontramos diversas referências a presentes em mantas dados pelos espanhóis, como esta que segue a respeito de um presente enviado aos principais tlaxcaltecas, que eram pobres e não possuíam mantas de algodão devido à opressão exercida pelos mexicanos:

Y nuestro capitán les dijo que se lo agradecía el buen consejo, y les mostró mucho amor, con ofrecimientos y dádivas que luego les dió al viejo Xicotenga y a Maseescaci, y a todos los más caciques, y les dió mucha parte de la ropa fina de mantas que habia presenteado Montezuma, y les dijo que sería bueno tratar paces entre ellos y los mexicanos para que tuviesen amistad y trajesen sal y algodón y otras mercaderías. (Diaz del Castillo: LXXIX).

É verdade que essas mesmas mantas poderiam ser utilizadas na negociação com os próprios mexicanos, da mesma forma que Moteczuma envia aos de Cholula um presente de ropas para que esses traíssem os espanhóis (Diaz del Castillo: LXXXIII) - o que representa uma prática tradicional, segundo a documentação. Entretanto é inegável que a presença forte dos espanhóis nas transações, ou melhor, 
negociações envolvendo mantas, é um indício claro de sua intervenção e manipulação dos antigos hábitos.

O fato de as mantas constituírem, aqui, quase exclusivamente, objetos de trocas cerimoniais, representa, já, uma séria distorção - ainda mais se pensarmos que a maioria dos presentes de mantas de índios para espanhóis vêm acompanhados também pelo ouro.

Em certa ocasião, Cortez presenteia os chefes tlaxcaltecas Xicotenga e Maseescaci com mantas: até aqui parece haver apenas um único elemento descaracterizador - a presença do espanhol. Mas, lembremo-nos de que mantas de algodão em Tlaxcala quase não existiam, pois a cidade, declarada inimiga dos mexicanos, sofria constantes ataques que a mantinham numa situação de pobreza vexatória (afinal, o algodão, como em muitas outras culturas era símbolo de riqueza e refinamento) e, sabendo disso, o hábil negociador resolve presentear a província no intuito de convencê-la a guerrear contra seus inimigos (Diaz del Castillo: LXXIX).

No caso do tributo, quando Moteczuma ofereceu ouro, jóias e pedras preciosas em tributo ao Imperador Carlos V - naturalmente, mediante a demanda espanhola -é possível mesmo que esse ato representasse, dentro da lógica indígena, uma concessão 'legítima' a um grande senhor que se impunha pela superioridade militar (Diaz del Castillo: XL). Mas do encontro dos dois interesses não é preciso dizer o que resultou.

As plumas são relativamente pouco citadas no relato do conquistador, com exceção daquelas mencionadas como adorno e objeto de prestígio e trocas cerimoniais. Nestas, apesar de dirigidas a espanhóis, podemos identificar práticas tradicionais, como em trocas cerimoniais de indios para espanhóis por ocasião da rendição do senhorio de Güeguiztlán em que vieram propor paz, trazendo un presente de oro de poca valía y plumaje de quetzales, que son unas plumas que se tienen entre ellos en mucho.... (Diaz del Castillo: CXVI).

Encontramos uma referência significativa envolvendo plumas relacionada à resistência do capitão Xicotenga, el mozo, em Tecuacinpacingo (um povoado de Tlaxcala), que recusava a proposta de aliança dos espanhóis, parecendo não se intimidar, nem dobrar-se aos seus caprichos. Na primeira proposta de paz, respondeu que comerían sus carnes (Diaz del Castillo: LXIV) e na segunda, após intervenção 
de seu pai e outros principais, por ser de mala condición y porfiado y soberbio, acordó de...enviar cuarenta indios con comida de gallinas y pan y fruta, cuatro mujeres, indias viejas y de ruin manera, y mucho copal y plumas de papagayos, y los indios que lo traían al parecer creíamos que venían de paz, y llegados a nuestro real sahumaron a Cortés, y sin hacer acato, como suelen entre ellos, dijeron: esto os envía el capitán Xicotenga que comáis, si sois teules (ídolos) bravos, como dícen los de Cempoal, y queréis sacrificios, tomad esas cuatro mujeres que sacrifiquéis...., y si sois teules mansos, ahí os traemos copal, que ya he dicho que es como incienso, y plumas de papagayos; haced vuestro sacrificio con ello (Diaz del Castillo: LXX).

Sabemos que tanto o presente quanto o sacrifício de plumas eram práticas vigentes em tempos pré-hispânicos. Mas, apesar de Tlaxcala ser uma provincia pobre, percebe-se claramente que a intenção do presente não era agradar: além da comida e das mulheres velhas, o presente limitado a copal e plumas - a julgar pela maneira tradicional de sacrificar - não era digno de um encontro diplomático. Certamente foi condicionado pelo desagrado diante da insistência e da cobiça dos europeus.

$\mathrm{O}$ espaço concedido por Bernal Diaz del Castillo às cuentas verdes, ou chalchihuites, é amplo e extremamente significativo. Apesar da frequiência menor do chalchihuitl, nesse texto, em relação a outras fontes - especialmente as de autoria indígena - é visível sua importância quanto à estima e valor.

Como no caso das mantas, esse objeto se destaca particularmente em contextos de trocas cerimoniais ou presentes. Existem diversas referências somente de presente de espanhóis para indios em chalchihuitl, já que, quaisquer pedras de cor verde mesmo as de vidro de Castela - recebiam essa designação entre os indígenas. Embora tenhamos notado que o valor do jade estivesse associado às águas e à fertilidade, lembremo-nos que, para os astecas, o verde representava a realeza. De fato o que se apreende do texto é que os chalchihuites autenticamene indígenas enviados a Cortez, - que constituíam o presente mais rico - não se destinavam a pessoas comuns. Após enviar presentes aos espanhóis em cargas de mantas de pluma fina e quatro chalchihuites, dizem os mensageiros de Moteczuma: 
... y que aquellas ricas piedras de chalchiuis que las envía para el gran emperador, y porque son tan ricas que vale cada una de ellas una gran carga de oro, y que en más estima las tenía y que ya no cure de enviar más mensajeros a México. (Diaz del Castillo: XL).

Presentes e tributos em chalchihuites - a pedra dos grandes senhores - para o Imperador Carlos V, embora também fosse um procedimento natural na visão de mundo indígena, implica, como observamos anteriormente, em desdobramentos totalmente estranhos àquela cultura.

Por outro lado, fica evidente que ao perceber a importância e o fascínio que a conta verde exercia sobre os indígenas, o conquistador tenha adotado a prática. Já no início do relato, Diaz del Castillo explica que ao virem alguns indígenas com pequenas jóias e galinhas para trocar com os espanhóis, estes pagavam em cuentas verdes y diamantes y otras joyas, y con aquello nos sustentábamos, porque comúnmente todos los soldados traíamos rescate, como teníamos aviso cuando los de Grijalva que era bueno traer cuentas. (Diaz del Castillo: XXXIX).

Seguem-se diversas referências a presente em cuentas verdes de Castilla ou apenas cuentas de Castilla (que seriam, provavelmente, verdes, em sua maioria), como esta em que dois caciques de Zacatula - onde os espanhóis estão explorando ouro - trazem um presente de ouro:

'Y Cortés se holgó tanto con el oro como si fueran treinta mil pesos en saber cierto que había buenas minas, y a los caciques que trajeron el presente les mostró mucho amor y les mandó dar cuentas verdes de Castilla, y con buenas palabras se volvieron a su tierra muy contentos.' (Diaz del Castillo: CIII).

Os chalchihuites eram também trocados por comida e serviços comuns, nos lugares onde os espanhóis se refugiavam durante a guerra de conquista, como na passagem da fuga do México narrada pelo cronista, em que todos buscavam levar o ouro:

Yo digo que no tuve codicia sino procurar de salvar la vida, mas no dejé de apañar de unas cazuelas [petacas] que alli estaban unos cuatro chalchiuis, que son piedras entre los indios muy preciadas, que presto me eché en los pechos entre las armas, que me 
fueran después buenas para curar mis heridas y comer el valor de ellas. (Diaz del Castillo: CXXVIII).

Ora, se cada chalchihuitl era avaliado pelos indígenas em uma carga de ouro, ou seja 17.250 gramas, o que correspondia a 3.750 castelhanos ou pesos de ouro (Farres 1985:371), e mais que isso, pertencia a uma esfera de prestígio, deduz-se que pagar comida e outros serviços com essas pedras constituía uma troca absurda (poderia fazer sentido, excepcionalmente em tal circunstância, dentro dos mecanismos de mercado, mas não no tipo de circulação em que tradicionalmente atuava) mas muito atraente para os indígenas, por questões de status - embora, a essa altura, todo o sistema que lhe conferia esse status estivesse já se desestruturando. Contudo, é bem provável que os indígenas tenham demorado um pouco a compreender isso dentro da confusão de valores que se instalou, e de qualquer maneira devem ter mantido dentro do possível o seu valor simbólico, religioso, que era extremamente forte. Com relação às trocas, no entanto, é possível que a prática tenha se reduzido drasticamente já que, as riquezas em pedras preciosas (no caso, aqui, a esmeralda) foram tragadas da América com destino à Europa. As demais pedras verdes como o jade, a serpentina, a obsidiana verde, o quartzo (Spence 1996; Lange 1993) devem ter desaparecido após o fim de suas importações - em função da desintegração do comércio de longa-distância realizado pelos pochteca (Chapman 1976), pois sabemos que não havia minas no México Central (Lange 1993).

Assim, Cortez vulgarizou ao extremo o trânsito dos chalchihuites - ou similares - que até então limitava-se a uma circulação nobre. Um artigo que era trocado entre os grandes senhores e em ocasiões solenes, passa a ser oferecido também a gente comum em troca de qualquer coisa: de alimentos, a prisioneiros recém-libertos, a mensageiros medrosos de sua missão como forma de encorajamento ou com o fim de atraí-los (Diaz del Castillo: LXIV; CXXXI).

Talvez resida aí a confusão a respeito do uso das contas de pedra verde como moeda comum: entre as fontes consultadas as únicas referências ao uso do chalchihuitl em troca de sustento, serviços e outros objetos do cotidiano, são todos pagos por espanhóis, o que representa já uma interferência européia. Que ele 
circulava como dom e pagamento nobre; que era artigo de venda e sobretudo utilizado em contextos cerimoniais e como adorno, fica muito evidente a partir da documentação. Contudo, o uso corriqueiro como moeda - como no caso da manta e do cacau - é, provavelmente, uma distorção causada pela conquista. Torna-se evidente que havia uma demanda por parte da população nativa em torno desse objeto e que Cortez ao percebê-la, decidiu manipulá-la em seu favor.

Podemos, enfim, afirmar que o chalchihuitl representa o caso mais dramático e ilustrativo na transformação da noção de valor: ao mesmo tempo em que, em tempos préhispânicos foi o objeto mais valorizado, no período da conquista foi o que teve o seu uso mais vulgarizado, diferentemente do ouro, que, a seu modo, era valorizado pelos espanhóis.

Com relação ao ouro, temos nesse texto uma quantidade de informações muito superior àquela relativa a outros objetos - o que não ocorre se tomarmos uma documentação mais ampla, em que ouro e mantas estão relativamente empatados. Essa tendência era esperada e representa a distorção mais óbvia em relação ao valor do ouro, ocorrida tanto no âmbito do concreto - a descaracterização das práticas tradicionais imposta pela Conquista - quanto no nível do relato e sua predileção por esse tema. Não há nada aqui, que possa concordar com o relativo equilíbrio revelado nas demais fontes onde o ouro é - sobretudo nas fontes indígenas - lembrado com moderação (França 1999).

O primeiro elemento que impressiona é a quantidade de 'dons' recebidos pelos espanhóis em ouro. Embora tenhamos testemunhos de que o ouro era um artigo de presente, é evidente que, neste caso, o comportamento é totalmente condicionado pela demanda espanhola, o que reflete uma situação já conhecidíssima, capaz de responder prontamente àquelas três primeiras questões formuladas acima - para quem? em troca de quê? e por quê?: para espanhóis, em troca de nada ou de pequenos objetos, e por imposição.

Obviamente, todas as referências coletadas são aquelas que usam o termo presente; entretanto, excetuando provavelmente os primeiríssimos contatos, a população indígena já sabia que tipo de presente os teules (deuses) queriam receber e o que poderia representar uma recusa, isso sem contar - o que o conquistador não 
conta, exceto nas pouquíssimas menções a demandar oro - as demandas explícitas do presente. É importante lembrar, que, nesse contexto, os espanhóis exerciam um forte domínio ideológico, na condição de prováveis deuses que vinham para cumprir a antiga profecia. Segundo Taxay, essa era a razão pela qual os índios entregavam o seu ouro em troca de qualquer coisa, embora concordemos que essa afirmação se aplica apenas aos primeiros momentos da Conquista (Taxay 1970:31).

Como observamos pouco acima, os objetos valiosos são sempre relacionados ao prestígio, mas o ouro envolve, nesse sentido, uma preocupação particular. Os adornos, jóias e divisas de ouro constituem objeto de descrições detalhadas e de grande cobiça e em alguns casos poderiam sugerir o saque, como nesta passagem relativa à Noche Triste:

‘...y las palabras que Cortés decía a los que andábamos envueltos con ellos, que la estocada o cuchillada que diésemos fuese en señores señalados, porque todos traían grandes penachos de oro y ricas armas y divisas...pués! que armas tan ricas que traían, con tanto oro y penachos y divisas, y todos los más capitanes y personas principales!' (Diaz del Castillo: CXXVIII).

Quanto ao contexto cerimonial, o número de referências ao ouro no texto de Diaz del Castillo é insignificante em relação aos demais documentos, o que reflete claramente a despreocupação do autor com os costumes indígenas - um traço típico de sua obra.

Por outro lado, os poucos presentes que os espanhóis fizeram aos indígenas constituem ocasiões políticas como aquelas à qual já fizemos referência anteriormente: são presentes para Moteczuma e para os senhores de Tlaxcala, em manta e chalchihuitl. Essas trocas sugerem um interpretação de mão dupla: se por um lado, os espanhóis não estavam nem um pouco interessados em desfazer-se de seu ouro, em troca por exemplo, de seu sustento, parece provável que os índios contentavamse muito mais com um presente de chalchihuitl de Castela do que com ouro.

Muito significativo da recondução da noção de valor indígena é, por exemplo, o fato de Cortez presentear com ouro e outros favores os indígenas que tivessem se destacado na guerra. Ora, sabemos que tradicionalmente aquele que obtivesse vitória militar adquiria a permissão para utilizar divisas especiais: jóias de ouro, mas tam- 
bém adornos de plumas, mantas ricas e chalchihuitl, títulos e ascenção social. (Torquemada: XIV-IV; Sahagún: IX-IV, 5). Embora o autor não especifique a forma do presente, sua expressão é significativa:

...y Cortés les habló y les dió muchas gracias y loores... Y con muchos prometimientos que les daría el tiempo adelante tierras y vasalos, los despidió, como estaban ricos y cargados de oro que hubieron y despojos, se fueron a sus tierras. (Diaz del Castillo, CLVI).

O impacto de tais interferências no sistema de troca tradicional teria, sem dúvida, um lugar de destaque na desestruturação da noção de valor indígena. Uma atividade de fundamental importância entre os indígenas mexicanos como a guerra - que concentrava em torno de si grande parte do valor atribuído àqueles objetos, representando uma das fontes mais poderosas de sua demanda - passa a ser recompensada com terra, vassalos e ouro, e é esse um dos caminhos pelo qual o metal vai perdendo seu significado de prestígio para significar riqueza, apenas. Não sabemos até que ponto e até quando o ouro conserva seu significado social, mas com toda a certeza, a avidez material do colonizador foi extremamente didática nessa reorientação do valor, principalmente porque ela própria criou a demanda do metal entre as populações nativas que dependiam dele, agora, para sobreviver, seja por meio de pagamento de tributos, taxas, e meio de troca para a subsistência, seja através do próprio trabalho nas minas. Nesse sentido lembremo-nos do Perú, estudado por Wachtel, onde o tributo em prata obrigava os índios a adotarem novas atividades em prejuízo das atividades tradicionais, acelerando ainda mais a desestruturação do mundo indígena (Wachtel 1971). Não foi diferente no México.

Além disso, nas trocas comerciais, os indígenas passaram a entregar seu ouro, senão à força, em troca de artigos de espanhóis que introduziam novos hábitos de consumo (Diaz del Castillo: XXXIX, XL, XLI, XIV). Ou seja, os índios passam a transferir, muitas vezes, as jóias de seus antepassados em troca de artigos totalmente alheios ao seu mundo - a situação parece ainda mais dramática, se levarmos em conta que o ouro, tradicionalmente, circulava em contextos cerimoniais (com 
exceção do ouro em pó e em barras). O contrário também é verdadeiro: espanhóis obtinham comida dos indígenas por intermédio de jóias de ouro, o que representa uma outra distorção, que é a utilização de objetos de prestígio na compra de gêneros de subsistência (Diaz del Castillo: XL, CXXVIII).

Vimos como o padrão de valor e riqueza era, por excelência, a posse das mantas de algodão e de sua matéria-prima, especialmente no caso de Tlaxcala. Por outro lado, ao observarmos o testemunho de Bernal Diaz del Castillo, percebemos que a relação riqueza/ ouro, pode muito bem constituir um artifício, diante de circunstâncias geradas pela demanda espanhola, como nessa passagem em que Xicotenga vem presentear Cortez:

...Y luego tendieron unas esteras y una manta encima, y trajeron seis o siete piecezuelas de oro y piedras de poco valor y ciertas cargas de ropa de henequén, que todo era muy pobre, que no valía veinte pesos, y cuando lo daban, dijeron aquellos caciques riendo: 'Malinche...es poco... somos pobres y que no tenemos oro ni ningunas riquezas, y la causa de ello es que esos traidores y malos de los mexicanos, y Montezuma, que ahora es señor, nos los han sacado todo cuanto solíamos tener, por paces y treguas que les demandábamos porque no nos diesen guerra;... (Diaz del Castillo: LXXXVI).

É assim que, inevitavelmente, por detrás de uma presença estranha vão se sucedendo uma série de práticas novas que produzem transformações imprevistas, com reações em cadeia. Mas o fenômeno é tão complexo que não podemos afirmar que os indígenas prontamente assimilaram a noção de valor ocidental e sim, que conviveram por muito tempo - muitos ainda convivem, segundo os dados etnográficos - com uma certa duplicidade relativa às duas esferas de valor. Afinal como bem nos ensinam os estudos sobre aculturação, "esta não se reduz a uma única marcha, à simples passagem da cultura indígena à cultura ocidental; existe um processo inverso, pelo qual a cultura indígena integra os elementos europeus sem perder suas características originais. Essa dupla polaridade confirma que a aculturação não pode ser reduzida à difusão, no espaço e no tempo, de traços culturais arbitrariamente isolados: trata-se de um fenômeno global que compromete toda a sociedade" (Wachtel, 1976). 


\section{Conveniência e influência recíproca}

Teríamos, enfim, muitos exemplos desse fenômeno, mas é importante ressaltar que a aculturação é também uma via de mão dupla, e que o conquistador, diante da necessidade de sobreviver ou mesmo do desejo de enriquecer, também foi presa desse quadro difuso de valores, principalmente aqueles para os quais o ouro não vinha com tanta facilidade. É o que revela o mesmo autor a respeito de alguns soldados de Pizarro que haviam ido a Tustepeque em busca de ouro:

\footnotetext{
Y preguntó Cortés por los demás soldados que había llevado Pizarro en su compañia... y dijo que porque les pareció muy bien aquella tierra y era rica de minas y los pueblos por donde fué muy de paz, les mandó que hiciesen una gran estancia de cacauhatales y maizales y pusiesen muchas aves de la tierra y otras granjerías que había de algodón, y que desde alli fuesen catando todos los rios y viesen qué minas había. Y puesto que Cortés calló por entonces, no se lo tuvo a bien a su pariente haber salido de su mandado; supimos que en secreto riñó mucho con él sobre ello, y le dijo que era de poca calidad querer entender en cosas de criar aves y cacahuatales. (Diaz del Castillo: CIII).
}

Note-se que a iniciativa de Pizarro e seus soldados envolve não apenas as minas de ouro mas outros artigos indígenas tradicionais - e quiçá estratégicos - como o cacau, a pluma e o algodão. E aos olhos do capitão, cujo acesso ao ouro era extremamente fácil, a busca dessas outras riquezas parecia uma bobagem. É provável que tenham existido muitas iniciativas como essa, levando-se em conta, naturalmente, as diferentes condições de materiais num contexto colonial: além de significar riqueza, vinham também atender necessidades da população como no caso do cacau, - na elaboração do chocolate, do algodão - na confecção do vestuário.

Um outro exemplo extremamente elucidativo dessa reciprocidade na aquisição cultural vem de um contexto arqueológico raríssimo encontrado em Chapingo: no enterramento $\mathrm{n}^{\circ} 43$, do tipo primário, junto ao esqueleto de um adulto do sexo masculino foi encontrada uma moeda cunhada por volta de 1554 na Casa de Moeda do México, conhecida como 'Carlos y Juana'. Isso por si só constitui um testemunho a favor da continuidade de uma prática tradicional de vincular o objeto monetário 
ao contexto funerário, tratando-se de uma substituição. Entretanto é significativo o fato de essa moeda conter juntamente com a esfínge dos reis, a denominação em caracteres indígenas (Pompa 1975). Tal prática por parte da cunhagem oficial denota uma necessidade de adequar-se ao universo indígena, com o sentido exato de favorecer a aceitação da moeda, é verdade, mas testemunha, por outro lado, as dificuldades relativas à penetração da moeda metálica no universo indígena, bem como as concessões e retrocessos por parte da cultura colonizadora.

\section{O ponto de vista indígena: transformação, desconcerto e manutençáo dos valores tradicionais}

Por detrás de todas essas práticas, o universo indígena iniciava um lento processo de fragmentação e uma outra concepção do valor, autônoma, percursora de uma nova forma de vida, ia nascendo na América.

Engana-se quem supõe que o fenômeno da mudança no valor tradicional (mais vivida do que pensada) tenha escapado à observação da população indígena. Aos acontecimentos relatados acima, corresponde uma percepção por parte do indígena de que algo viera interferir na sua antiga forma de conceber o valor das coisas e das pessoas. No Relato da Conquista (texto anônimo de Tlatelolco) - escrito nos primeiros anos da conquista - o fenômeno era sentido com pesar entre os índios, - embora ainda de maneira difusa. Fala-se diversas vêzes das divisas e insígnias de guerra, dos diversos adornos a distinguir os homens e os deuses como objetos de riqueza e alvo da cobiça dos conquistadores (Relato Anônimo: vs. 18; 51; 86; 108; 111). E diante da demanda dos espanhóis, alguns capitães tlatelolcas vão à presença de Cortez:

Aqui está esto con que vienen a implorarte: esto es lo que estaba en las orejeras y en los escudos de los dioses de tus vasallos. (idem, v. 111).

Nota-se o desconcerto do narrador (e das personagens por detrás da narrativa), ao constatar que um gesto de tamanho sacrifício, como abrir mão de objetos tão valiosos, tenha merecido apenas uma repreensão pelo fato de ser a quantidade do ouro muito pequena. $\mathrm{O}$ texto revela grande dificuldade por parte do indígena em compreender essa conversão de valores sociais, morais, simbólicos - qualitativos - 
em valores materiais e quantitativos. Vislumbra-se, já, uma literal e completa inversão dos valores - fenômeno, para eles, incompreensível:

Se nos puso precio. Precio del joven, del sacerdote, del niño y de la doncella. Basta: de un pobre era el precio sólo dos puñados de maíz, sólo diez tortas de mosco: era nuestro precio veinte tortas de grama salitrosa.

Oro, jades, mantas ricas, plumajes de quetzal, todo eso que es precioso, en nada fue estimado. (idem v. 86).

E um pouco adiante, ao referir-se ao estabelecimento dos espanhóis na terra, o autor observa:

'Luego se les dieron indios vasallos en todos estos pueblos. Fue entonces cuando se dieron personas en don, fue cuando se dieron como esclavos.' (idem, v. 125).

Diríamos, ironicamente, que aí estava mais uma inovação dos conquistadores em termos de troca. A expressão personas en don é muito significativa acerca da sobrevivência de categorias indígenas de pensamento. Por outro lado, o fato de vir acompanhada de uma outra, expressiva da situação colonial - dieron como esclavos - reflete, sem dúvida, a forma dúbia e contraditória com que os índios analisavam as novas práticas. Isto porque, se o costume de obter escravos através de conquistas era largamente difundido em tempos pré-hispânicos, jamais, entretanto, constituíam objeto de dom, senão aos deuses.

A Relación..., de Fernando Ixtlilxóchitl, tem um caráter mais mestiço, mas nem por isso deixa de observar o pouco caso dos espanhóis quanto aos presentes de ouro dados por seus antepassados. A diferença é que escrevendo nos primórdios do século XVII, Ixtlilxóchitl o faz de uma forma mais objetiva - diríamos assimilada inclusive chamando a atenção, freqüentemente, para codicia del oro dos espanhóis (Ixtlilxóchitl, vs. 13, 15, 24).

Em uma ocasião, segundo o autor, Cortez prendeu o irmão de Ixtlilxuchitl (trisavô do cronista) e mandou pedir ouro como resgate. Então "le respondió que si no quedaba más que por el oro, que más quería la salud de su hermano que cuantos 
tesoros tiene el mundo, y así envió a Tezcoco por el oro que había quedado en los palacios de su padre y abuelo y por todo lo que él tenía en sus casas, y se lo dió a Cortés: el cual dijo que era poco para rescatar a un gran señor como era su hermano, y que era menester más" (idem, v. 190).

A vida humana, antigamente expressa num valor social, coletivo, passa - com a introdução da noção de valor européia - a ser intercambiável com o ouro ou quaisquer objetos possuidores de valor econômico, em favor do interesse individual.

É evidente, nesta passagem - como no Relato Anónimo - a perplexidade tanto dos personagens do drama quanto do próprio autor: o relação de valor que os espanhóis atribuíam às pessoas e ao ouro era, para eles, imcompreensível. De um lado, os conquistadores estabeleciam equivalências entre ouro e pessoas; de outro, os indígenas respondiam que não havia ouro que valesse a vida de seu irmão; e por fim, aqueles utilizavam seus argumentos para pedir mais ouro.

Além do tom perplexo - no caso do autor da Relación, indignado, pela pobreza em que caíra - esses testemunhos, encontráveis somente nos relatos indígenas da Conquista, nos transmitem um profundo sentimento de angústia e impotência por parte daqueles que buscavam encontrar, talvez, uma explicação. A explicação de um mundo em que viam diluídas as suas referências e seus valores em meio a uma outra racionalidade que era para eles, ainda, incompreensível.

Mas não somente a vida humana, como também a dos deuses, e com elas, todo o antigo sistema de crenças: quando da conquista de Tenochtitlán, ao invadirem o templo de Huitzilopochtli, conta o historiador que "Cortés cogió la máscara de oro que tenía puesta este ídolo con ciertas piedras preciosas que estaban engastadas en ella. Ixtlilxuchitl le cortó la cabeza al que pocos años antes adoraba por su Dios" (idem, v. 105). Obviamente, ajudar a arrancar o atavío precioso de um deus principal e cortar-lhe a cabeça, após tão pouco tempo de contato, parece-nos um gesto teatral, ou fruto de uma narrativa aculturada, de conteúdo extremamente ideológico. Não é improvável que tenha sido forjado pelo autor, o qual, não obstante suas críticas aos conquistadores, precisava legitimar-se enquanto aliado da conquista e bom cristão, a fim de obter, em tempos de dificuldades, os favores de Sua Majestade. 
No entanto, o que fica é a observação muito clara do autor acerca da reorientação na noção de valor, que permite que a imagem de um dos pilares do império indígena seja destruída em troca de algumas pedras preciosas. Algumas poucas pedras, que anteriormente serviam para coroar e realçar o poder de uma entidade, que, na verdade, era possuidora de todas as pedras preciosas do Império, passam a ter um valor superior ao de seu antigo possuidor - e aqui temos um exemplo concreto de como a reelaboração da noção de valor está essencialmente vinculada à mudanças dos valores gerais da antiga sociedade indígena.

Num outro exemplo, extremamente elucidativo, o testamento, já citado, de D. Julián de la Rosa de 1566 nos diz:

A pessoa doente diz: eu solicito aos padres que me façam a caridade de dizer cinco missas para mim. Minha oferta será que meu cavalo será vendido, e vai sem a sela; o preço do cavalo será para dizer missas. E uma manta trançada minha será vendida, e será dedicada para dizer missas, e uma manta emplumada minha, com plumas de patos, deverá ser vendida, e tambem irá para dizer missas e ser uma oferta. E duas mantas de algodão muito finas serão vendidas e dedicadas também para dizer missas, uma delas de algodão amarelo, e outra com um desenho de cesta de flores. (Anderson, Berdan e Lockhart 1976: 46,47).

A continuidade na valorização desses objetos choca-se com as necessidades de uma nova realidade, de forma quase irônica: vendê-los por dinheiro para pagar missas. Objetos preciosos, que anteriormente acompanhavam seu possuidor na cerimônia fúnebre e garantiam seu lugar no além-túmulo, agora necessitam ser substituídos por dinheiro para serem trocados por um outro tipo de acesso à outra vida, baseado nos princípios espirituais da nova religião. Note-se - pelo emprego dos termos oferta e dedicado (traduzidos diretamente do náhuatl para o inglês como offering e devoted) - a ligação que o testador estabelece entre os objetos tradicionais (com a exceção do cavalo) e a oferta às entidades celestiais, o que denota um certo grau de manutenção dos antigos valores. 
Resumindo, trata-se de transformar (ou transtornar) o significado global desses objetos nas esferas de valor cerimonial e de prestígio, destacando-os de seu contexto original holístico, para assumir um papel econômico autônomo, nos moldes ocidentais.

Por outro lado, podemos constatar, sem dificuldade, a continuidade na valorização dos objetos preciosos no imaginário indígena. $\mathrm{O}$ que ocorreu, na verdade, não foi a supressão, simplesmente, da antiga noção de valor, mas uma adaptação desta aos novos moldes de valor impostos pela situação colonial.

Os antigos objetos continuaram, ainda, incorporando valor como parte dos recursos de manutenção da identidade indígena. Os livros pintados haviam sido em sua maioria destruídos; a tradição oral, responsável pela elaboração de novos livros com elementos coloniais, poderia em algum momento perder-se; a linguagem, os costumes, iam pouco a pouco se modificando. Mas os objetos podem permanecer por muito tempo, e ainda que o seu significado original não possa ser expresso, podem encerrá-lo em suas formas ou substância.

Não é fato sem importância que Ixtlilxochitl, escrevendo já no limiar do século XVII, faça menções repetidas às formas tradicionais de riqueza (Ixtlixóchitl, 111, 180, 258, 296, 388, 389) como esta que segue, acerca de uma expedição a Hibueras:

Dicen que el mejor ejército que se sacó de Tezcoco para las partes referidas era de más de cinco mil soldados, los cuales Ixtlilxúchitl siempre proveía de todo lo necesario, así de sustento como de vestuario, de armas y de otras muchas cosas necesarias, y muy buenos premios, según la antigua costumbre... (idem, v. 388).

E a respeito do despojo de Tenochtitlán:

Este día, después de haber saqueado la ciudad, tomaron los españoles para sí el oro y plata, y los señores la pedrería y plumas, y los soldados las mantas y demás cosas, y estuvieron después de esto otros cuatro en enterrar los muertos... (idem,v. 180).

Percebe-se que na memória do autor ainda está muito clara a distinção dos valores indígenas e europeus: para os espanhóis, ouro e prata; para os senhores, pedrarias e plumas (materiais de adorno e divisas); e para os soldados (indígenas) man- 
tas y demás cosas (valores mais comuns, pois as mantas, ao serem substituídas pelo peso, já não tinham o mesmo valor).

Em algum momento, portanto, para o México ou para a América como um todo, homens de diferentes mundos encontraram-se pela primeira vez, trocando objetos e valores e desencadeando um processo de desmembramento de um universo integrado, único, em segmentos estanques, sobre os quais começa a surgir, imperativa, uma lógica de mercado que tudo submete. Mas a resistência indígena encontrou inúmeras formas de perpetuar sua memória, mesmo em meio a manifestações plenas de hibridismo que, embora naturais e espontâneas para seus agentes, deixam entrever os intrincados mecanismos de sobreviência cultural e preservação da identidade.

\section{Considerações finais}

Os antigos mexicanos do Altiplano Central, atribuíram, portanto, um significado muito particular aos seus objetos preciosos, cuja natureza e complexidade depende da relação que se estabelece com todas as instâncias da sociedade, dentro de um contexto de práticas sociais integradas pelo que se convencionou chamar fato social total (Mauss 1971). Assim, no Império Mexica - sociedade do tipo arcaica, apresentando um mercado bastante desenvolvido - encontramos, já, o embrião do dinheiro moderno sob a forma de ouro em pó, de um valor utilitário, ou do cacau, cujo valor remete, ainda, a um contexto ritual. Mas também encontramos a ambivalência no valor das mantas - comercial e nobre a um tempo - a reverência ao chalchihuitl e às plumas - objetos monetários valorizados em função de suas qualidades políticas, sociais, míticas e rituais, típicas de uma sociedade de mercado que retém as práticas culturais e organização social tradicionais.

A continuidade no uso dos objetos tradicionais foi uma realidade no período colonial, enquanto que a capacidade de sobrevivência dos objetos monetários variou de acordo com a conveniência do conquistador e as necessidades locais: a manta, por exemplo, foi destituída de sua função de padrão de valor e de troca devido à equivalência com o peso espanhol; outros como o cacau mantiveram uma sobrevida que chega até mesmo aos dias atuais. 
A verdade é que, na medida em que o dinheiro opera segundo uma convenção ou um consenso em torno de seu valor, e este, por sua vez, está essencialmente vinculado aos valores tradicionais de uma determinada sociedade - a Asteca, nesse caso a transição para uma noção de valor econômica não poderia ser natural e automática, como pretendem alguns, antes envolvendo uma série de questões que dizem respeito à desagregação da cultura indígena como um todo. Desse modo, a introdução da cultura européia em todos os seus aspectos contribuiu, sem dúvida, para a descaracterização da noção de valor indígena. Ora, se um dos principais fundamentos do valor dos objetos preciosos na cultura mexica repousa sobre o contexto mágico-mítico, o que dizer dos efeitos da nova religião na desestruturação da antiga noção de valor?

Mas, da mesma forma que as transformações culturais interferiam na elaboração de uma nova noção de valor, esta também trabalhava em favor da destruição do antigo modo de vida, acelerando o processo.

Assim, embora o metal fosse também valioso para os indígenas, a natureza de seu valor era bastante diferente para ambas as culturas. $\mathrm{O}$ ouro era objeto de estima e meio de troca tanto na cultura indígena quanto na européia. Para a primeira, porém, o seu valor repousava basicamente, além dos fatores universais beleza e raridade, na sua qualidade de matéria-prima para confecção de jóias e ornamentos de homens e deuses - vinculada, portanto, às esferas de prestígio e ritual - enquanto que entre os europeus, encontramos já, para além do fascínio, um significado econômico bastante preciso.

Ao se inaugurar a corrida do ouro na América, esse material perdeu, quase prontamente o seu papel tradicional, em função do monopólio espanhol sobre todo o ouro encontrado - o que o fez desaparecer dos contextos tradicionais, deixando para sempre uma lacuna no sistema de valor indígena, que passará a contemplá-lo como parte de um passado distante, registrado nos livros pintados, além da tradição oral. A partir de então, o ouro passa a encarnar o único valor possível dentro do contexto colonial, que é o do equivalente universal. Mas o mais surpreendente é que, se por um lado, o ouro perde o seu significado tradicional quase que instantaneamente, por outro, levanta-se como símbolo de uma nova forma de pensar e agir, cujo valor direciona e determina todas as outras esferas da vida, fenômeno até então desconhecido na sociedade indígena. Um 
elemento que operava basicamente em esferas de prestígio e cerimonial, adquire, então, um outro significado, totalmente novo, que unifica as esferas, agora, sob sua atuação.

Em um outro exemplo desse tipo de distorção - a compra de comida pelo chalchihuitl, um símbolo de prestígio entre os mexicanos - observamos que, na medida em que Cortez manipulou o chalchihuitl (entre outros objetos) para empregálos em contextos estranhos à sua circulação tradicional, ele estava, inconscientemente, contribuindo para a desestruturação dessas esferas de circulação. Ao transtornar, por um lado, o valor do chalchihuitl, que passa a operar em contextos até então inéditos, e ao tornar equivalentes, por outro lado, as esfera de subsistência e prestígio, o conquistador destruía todo o sistema social indígena. Assim, muito mais que distorcer o significado do objeto e seu valor, a introdução do valor econômico veiculada através do equivalente universal, constituiu, no México Central, assim como em toda a América, um elemento importantíssimo na desestruturação da cultura indígena em seu conjunto.

Todo o problema, enfim, reside no impacto do dinheiro universal. Em um sistema social de economia multicêntrica, que conhecia, no mínimo, duas esferas de valor bem definidas, com a utilização de diferentes objetos para fins específicos, a entrada do dinheiro unificador - que provê um denominador comum entre todas as esferas, tornando todas as coisas intercambiáveis entre si, e expressáveis em termos de um único padrão - possui um efeito devastador (Bohannan 1967).

No furacão do nascente capitalismo europeu, a América perdeu para sempre a integridade de seus valores, nascendo moderna, mutilada, sob a lógica fragmentada da razão renascentista e a moeda metálica e a noção de valor que lhe é correspondente, tomaram, assim, o seu lugar na vida econômica do México, com todas as suas conseqüências destrutivas.

Mas o fato é que se o objeto precioso perdeu, por assim dizer, o seu papel de instrumento monetário, é verdade também que manteve suas outras características relativas ao valor tradicional, apesar da unificação das esferas. É como se tivesse sido substituído pela moeda apenas naquela área específica do valor comercial: para uma noção de valor estranha, alienígena, um objeto correspondente - a moeda; para 
a preservação da memória e da identidade de um sistema de valores integrados, os objetos preciosos, os quais permanecem símbolos de valores e práticas ancestrais, mantendo-se preservados em suas múltiplas significações culturais. A utilidade monetária desaparece, mas ofetiche - que é a causa de sua escolha, se mantém.

O Testamento de D. Julian de la Rosa traz um exemplo singelo dessa reorientação da noção de valor dos antigos objetos monetários. Se por um lado, eles devem ser vendidos em troca de dinheiro e missa, por outro, o documento atesta uma profunda reverência e estima pelos antigos objetos, os quais deveriam ser guardados por toda a vida:

E o escudo com 200 plumas de quetzal, deve ser deixado como está: ele deve se mantido sob a guarda de Diego Bautista...outras plumas de quetzal deverão também ser guardadas tal como estão. (Anderson, Berdan e Lockhart, 1976: 51)

Como bem observou o rei-poeta Nezahualcóyotl, os homens não podem transformar-se em jade ou ouro. Mas, talvez, D. Julián, no anseio de deixar algo de si, tenha percebido que esses objetos simbolizavam os últimos testemunhos de um antigo modo de vida - que em última análise significa Cultura - cuja sobrevivência deveria ser garantida para além da vida do indivíduo. E para nós, felizmente, restou a possibilidade de vislumbrar traços da antiga cultura através desses objetos - vestígios de um universo integrado, com sua curiosa misteriosa eloqüência, à espera de um olhar curioso que lhes venha desvendar o sentido.

\section{Referências Bibliográficas}

ANDERSON, A.J.O., BERDAN, F. e LOCKHART, J. Beyond the Codices. The Nahua View of Colonial Mexico. Berkeley, Los Angeles, London, University of California Press, 1976.

BERDAN, F. F. The Aztecs of Central Mexico. An Imperial Society. New York, Holt, Hinehart and Winston. Case studies in Cultural Anthropology, 1982.

Trade, Tribute anda Market in the Aztec Empire. Doctoral dissertation, Austin, University of Texas Press, 1975. 
BOHANNAN, P. 'The Impact of Money on an African subistence Economy'. In G. Dalton, Tribal and Peasant Economies. New York, The Natural History Press, 1967, pp. 123-135.

CHAPMAN, A. 'Puertos de comercio en las civilizaciones Azteca y Maya'. In K. Polanyi, C. Arensberg, H. Pearson, Comercio y Mercado en los Imperios Antiguos. Barcelona, Labor Universitaria, 1976, pp. 163-200.

Codice Chimalpopoca. Anales de Cuauhtitlán y Leyenda de los soles. México, UNAM, 1975. Trad. direta do náhuatl por Primo Feliciano Velázques.

CONRAD, G.W. e DEMAREST, A.A. Religión e imperio. Dinámica del expansionismo azteca e inca. México, Consejo Nacional para la Cultura y las Artes/Editorial Patria, 1990.

DALTON, G. Primitive, Archaic and Modern Economies. Boston, Beacon Press, 1968. Tribal and Peasant Economies. New York, The American Museum of Natural History, The Natural History Press, 1967.

DIAZ DEL CASTILLO, B. Historia Verdadera de la Conquista de la Nueva España. México, Editorial Porrua, 1977.

EINZIG, P. Primitive Money. Glasgow, Blackie and Son Ltd., 2a. ed. (revised and enlarged), 1966.

FARRES, G. 'Los Españoles en las Indias Occidentales. Exploraciones, Tesoros, Monedas'. Nusmismatica e Antiquità Classiche. Vol. 12, 1983, pp. 305-331; vol. 13, 1984, pp.285305; vol 14, 1985, pp. 367-392; vol. 15, 1986, pp. 317-340; vol. 16, 1987, pp. 303-335.

FRANÇA, L. M. Transformações da Noção de Valor na Mesoamérica: os 'Objetos Preciosos' como Intermediários nas Trocas Indígenas e o seu Encontro com a Moeda Metálica. São Paulo, F.F.L.C.H./USP, 1999 (Dissertação de Mestrado).

GERNET, L. 'La notion mythique de la valeur en Grèce'. Journal de Psycologie, 1948, pp 415-462.

GIBSON, C. Los Aztecas bajo el domínio espanhol: 1519-1810. México, siglo Veintiuno, 1991, (11a. edição).

HERRERA, A. Historia general de los hechos de los castellanos en las Islas y Tierra-Firme de el Mar Océano. Asunción, Ed. Guarania, 1726-1730;

IXTLILXÓCHITL, Fernando de Alva. Obras Historicas. México, UNAM, 1975.

LANGE F. W. Precolumbian Jade: New Geological and Cultural Interpretations (ed.). Salt Lake City, University of Utah Press, c1993.

LAS CASAS, Bartolomé, Frei. Los indios de México y Nueva España. Antologia. México, Editorial Porrua, 1971. 
MAUSS, M. 'Ensaio sobre los dones. Razón y forma del cambio en las sociedades primitivas'. In Sociologia y Antropologia, Madrid, Editorial Tecnos, 1971. Parte II. pp. 155-263.

MORENO, R. 'Las instituciones de la industria minera novohispana'. In M. León-Portilla, J.G. Lacroix, R. Moneno e E.M. Bracho, La Minería en México. México, UNAM, 1978.

OROZCO Y BERRA, M. Apuntes para la historia de la moneda y acuñación en México desde antes de la conquista. México, 1880, apud Farrés, 1986, op. cit., p. 320.

POLANYI, K. A Grande Transformação. Rio de Janeiro, Ed. Campus Ltda., 1980.

'Semantics of Money-Uses'. In G. Dalton, Primitive, Archaic and Modern Economies. Essays. Boston, Beacon Press, 1968, pp. 175-203.

POLANYI, K., ARENSBERG, C. M., PEARSON, H.W. Comercio y Mercado en los Impérios Antiguos. Barcelona, Labor Universitária, 1976.

PRYOR, F.L. The Origins of the Economy. A Comparative Study of Distribution in Primitive and Peasant Economies. Nova Iorque. Academic Press, 1977.

QUIGgIN, A. H. A Survey of Primitive Money. The beginning of Currency. Nova Iorque, Barnes \& Noble, Inc/Londres, Methuen \& CO. Ltd., 1949.

Relato de la Conquista por un autor anónimo de Tlatelolco. In. B. Sahagún, Historia General de las Cosas de la Nueva España. México, Editorial Porrua, 1975, pp. 813-822.

ROJAS, J. L. de. 'La moneda indígena en México'. Revista Española de Antropologia americana, no. XVII. Ed. Universidad Complutense de Madrid, 1987, pp 75-88.

SAHAGÚN, Bernardino, Frei. História General de las Cosas de la Nueva España. México, Editoria Porrua, 1975.

TAXAY, D. Money of the American Indians and other Primitive Currencies of the Americas. Nova Iorque, Arco Publishing Company, Inc. 1970.

TEZOZÓMOC, Fernando de Alvarado. Crónica Mexicayotl. México, UNAM, 1975. Tradução direta do náhuatl por Ádrian León.

TODOROV, T. A Conquista da América. a questão do outro. São Paulo, Martins Fontes, 1988.

TORQUEMADA, Juan de. Monarquia Indiana. México. UNAM, 1975-1983.

WACHTEL, N. 'A Aculturação'. In J. le Goff e P. Nora, Historia: Novos Problemas. Rio de Janeiro, Ed. Francisco Alves, 1976, pp. 113-129.

'La destructuration economique'. La visión des Vaincus. Les Indiens du Peróu devant la Conquête Espagnole, 1530-1570. Paris, Gallimard, 1971. 